\title{
Intercostal celiotomy for removal of proventriculus foreign body in muscovy duck (Cairina moschata): case report
}

[Celiotomia intercostal para remoção de corpo estranho do proventrículo de pato-do-mato (Cairina Moschata): relato de caso]

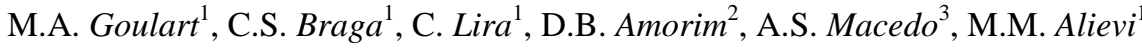 \\ ${ }^{1}$ Universidade Federal do Rio Grande do Sul - Porto Alegre, RS \\ ${ }^{2}$ Centro de Estudos Costeiros - Universidade Federal do Rio Grande do Sul - Imbé, RS \\ ${ }^{3}$ Universidade de São Paulo - São Paulo, SP
}

\begin{abstract}
Ducks, geese and swans are included in the Anatidae family, Anseriformes order. The leading injuries causes to waterfowl are tangling in fishing materials and foreign bodies ingestion. A muscovy duck (Cairina moschata) was referred for treatment at Veterinary Teaching Hospital and a radiographic examination showed the presence of a hook in the coelom. Surgical exposure and incision of the proventriculus was made through left intercostal access and the hook along with a fishing line were gently removed. The animal began to feed voluntarily at the fourth post-operative day and two weeks after the procedure the patient was clinically well and was released to wild. This surgical approach differs in some aspects from the listed techniques in the known literature. It proved to be a viable and appropriate alternative to treat this affection since it did not cause any trans- or post-operative complications and enabled rapid recovery and subsequent patient release.
\end{abstract}

Keywords: hook, gastrointestinal surgery, proventriculotomy, waterfowl, avian surgery

\section{RESUMO}

Patos, gansos e cisnes estão incluídos na família Anatidae, ordem Anseriformes. Entre as principais causas de ferimentos em aves aquáticas, o embaraço com materiais de pesca e a ingestão de corpos estranhos são os mais citados. Um pato-do-mato (Cairina moschata) foi encaminhado para tratamento no Hospital Veterinário e, mediante exame radiográfico, verificou-se a presença de um anzol na cavidade celomática, provavelmente no proventrículo. Utilizando-se o acesso intercostal esquerdo, foi feita a exposição e a incisão do proventrículo. Por meio dessa incisão, o anzol com um segmento de linha de pesca foi delicadamente retirado. O animal começou a se alimentar voluntariamente no quarto dia pósoperatório e duas semanas após o procedimento o paciente se encontrava clinicamente bem e apto à soltura. Esta abordagem cirúrgica difere, em alguns aspectos, das técnicas listadas na literatura e provou ser uma alternativa viável e adequada ao caso, não causando complicações e permitindo recuperação rápida, com posterior soltura do animal.

Palavras-chave: anzol, cirurgia gastrointestinal, proventriculotomia, aves aquáticas, cirurgia em aves

\section{INTRODUCTION}

Ducks, geese and swans are from the family Anatidae, Anseriformes order (Cândido, 2014). Urbanization harms some Anseriform populations for a variety of reasons ranging from habitat invasion to direct contact with exotic

Recebido em 15 de maio de 2017

Aceito em 9 de novembro de 2018

E-mail: miuriel.vet@gmail.com fauna and human activities such as fishing. Brazil has more than eight thousand kilometers of coastline and 8.2 billion cubic meters of freshwater distributed in rivers, lakes, reservoirs and dams, which strengthens amateur fishing (Brasil, 2014). In places where fishing is a popular activity, interaction between waterfowl and fishing equipment is common, with emphasis on accidental entanglement in fishing 
nets and foreign bodies ingestion (Routh e Sanderson, 2010; Cândido, 2014).

Nylon monofilament is a strong and elastic material currently used in fishing. It persists in the environment and is barely visible in water, and can easily be lost or discarded recklessly, along with hooks, baits or sinkers, on the ground and in the peripheral vegetation above or below water, creating invisible obstacles (Routh e Sanderson, 2010).

The anseriformes birds feeding habits, filtrating floating food on water, makes them vulnerable to foreign body ingestion, from plastic to metallic objects. A fish hook interspersed with aquatic vegetation can be ingested without the bird having noticed it; however, due to the food filtration mechanism, they are rarely swallowed (Anderson, 2004). They are more frequently found with the nylon thread, causing dysfunction in other places such as skin, ligaments, tendons lacerations or even amputations secondary to ischemic necrosis caused by a tourniquet. It is therefore the standard procedure when birds have any line hanging in the oral cavity to first inspect for the presence of entangled fishing material externally or around the beak, tongue or glottis (Routh and Sanderson, 2010; Cândido, 2014).

The purpose of this paper is to describe the removal of a fish hook from the proventriculus of a muscovy duck using the left intercostal surgical approach.

\section{CASE REPORT}

A female muscovy duck (Cairina moschata) of $1.35 \mathrm{~kg}$ body weight, was referred to the Veterinary Teaching Hospital after been found in a fishing area with a history of nylon thread exposure in the oral cavity.

At clinical examination the animal was active, with mildly pallid mucosa, cloacal temperature of $40.5^{\circ} \mathrm{C}\left(104.9^{\circ} \mathrm{F}\right)$, heart rate and respiratory rate within the normal range for the specie, and a 2.5 body condition score (on a scale from 1 to 5 ). The nylon thread reported was not evidenced in the oral cavity. Simple radiographic examination in laterolateral and ventrodorsal projections revealed a hook in the center of the coelomic cavity, presumed proventriculus, and some small linear fragments of metallic radiopacity in the ventricle region (Figure 1A-B).

The patient received tramadol hydrochloride (Tramadol@, União Química, São Paulo/SP, Brazil) 30mg. $\mathrm{kg}^{-1} \mathrm{q} 12 \mathrm{~h}$ IM or IV and metamizole (D-500®, Zoetis, São Paulo/SP, Brazil) 25mg.kg${ }^{1} \mathrm{q} 12 \mathrm{~h}$ VO for six days, also vitamin and mineral supplement (Maltodex Pet $\AA$, Duprat, Rio de Janeiro/RJ, Brazil) 0.2mL q12h VO and Bella ave ${ }^{\circledR}$ every day (Ourofino Pet, Osasco/SP, Brazil) 2 drops q12h VO for five days. Fasting was done until the second hospital day, for serial contrast-enhanced radiographic examination in order to assess the integrity and motility of the gastrointestinal tract (GIT). Iohexol (Omnipaque®, GE Healthcare do Brasil, Contagem/MG, Brazil) $25 \mathrm{~mL} . \mathrm{kg}^{-1}$ diluted $1: 1$ in water via gavage needle) was the contrast medium used and there was no contrast media extravasation on the GIT and gastrointestinal transit was adequate (Figure 1C-D).

As the animal was inactive, but with intact GIT, gavage was started with fruits and leaves. The medial metatarsal vein was catheterized for continuous administration of $0.9 \% \mathrm{NaCl}$ solution with multivitamins (Frutovitam ${ }^{\circledR}$, Cristália, Itapira/SP, Brazil) at a fluid rate of $2.5 \mathrm{ml} / \mathrm{kg} / \mathrm{h}$, with a universal IV administration set, for maintenance of hydration status and micronutrients until the surgical procedure to remove the foreign body.

For the surgical procedure, the animal received butorphanol tartarate as premedication (Torbugesic®, Zoetis, São Paulo/SP, Brazil) $1 \mathrm{mg} . \mathrm{kg}^{-1}$ IM and, after 15 minutes, general anesthesia was induced with isoflurane vaporized in $100 \%$ oxygen through a mask. When the patient reached an adequate anesthetic stage, it was intubated with a 2.5 uncuffed endotracheal tube and general anesthesia was maintained with the same anaesthetic agent in a universal vaporizer.

The patient was maintained in right lateral recumbency and feathers was plucked from the left lateral region of the body, the skin was prepped with $4 \%$ chlorhexidine gluconate solution. After the draping process was done, a $0.5 \mathrm{~cm}$ skin incision was made in the region of the fourth left intercostal space. 

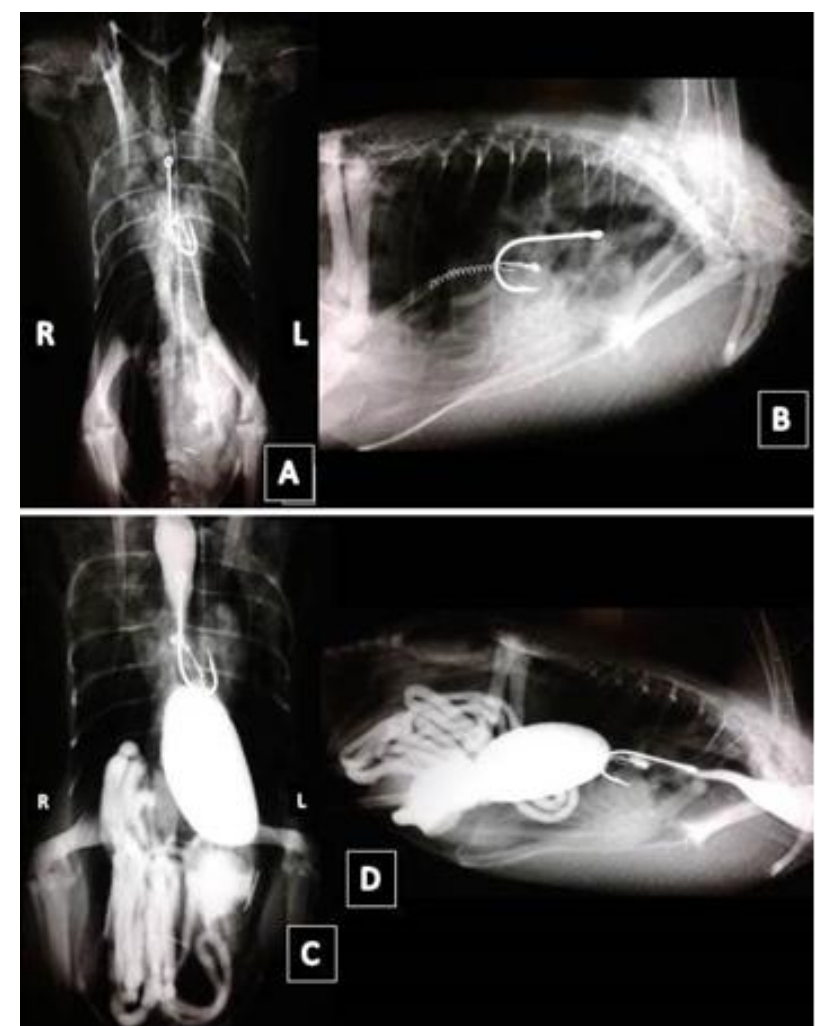

Figure 1. Muscovy duck (Cairina moschata):A-B. Simple x-ray in the ventro-dorsal and laterolateral projections evidencing a hook in the central region of the coelomic cavity. C-D. Radiography with iohexol contrast in the ventro-dorsal and laterolateral projections showing no extravasation of contrast in the GIT.

After blunt dissection of pectoral and intercostal muscles, the coelomic cavity was accessed and the left anterior thoracic air sac was ruptured. Through this incision, a $4 \mathrm{~mm}$ diameter optical was inserted to perform video laparoscopy to identify the exact position of the hook, as well as to assess its relation with adjacent organs and regional blood vessels to verify the possibility of video-assisted removal. However, it was not possible to visualize the hook and enlargement of the surgical incision (approx..5cm) was performed to allow open removal.

Through palpation, a rigid hook-like structure was perceived within the proventriculus. Two stay sutures were made in the organ for better manipulation (Figure 2A). Subsequently, a scalpel blade was used to make a stab incision and two additional repair points were made, and the incision was enlarged with a Metzenbaum scissors (Figure 2B). Through this incision, the hook with a fishing line segment and a hook-end were gently removed (Figure 2C-D).
After viability assessment of the viscera, suture was performed with 3-0 polyglycolic acid in simple isolated pattern. Intercostal muscles received the same suture. Skin was apposed with single interrupted pattern with 3-0 nylon monofilament.

On the postoperative days, intravenous fluid therapy $(0.9 \% \mathrm{NaCl}$ solution with Frutovitam®) was administered at a fluid rate of $2.5 \mathrm{ml} / \mathrm{kg} / \mathrm{h}$, with a universal IV administration set until day 2 postoperative. Also, tramadol hydrochloride (30mg. $\mathrm{kg}^{-1}$ IV q12h), metamizole (25mg. $\mathrm{kg}^{-1} \mathrm{IV}$ $\mathrm{q} 12 \mathrm{~h}$ ), and sucralfate (Sucrafilm®, EMS, Hortolândia/SP, Brazil), 25mg.kg ${ }^{-1}$ VO q12h for six days. The antimicrobial therapy was based on penicillins and streptomycin (Pentabiotico Veterinário®, Zoetis, São Paulo/SP, Brazil) $0.1 \mathrm{~mL} . \mathrm{kg}^{-1} \mathrm{IM}$, administrated on day 0 and day 5 postoperative. 


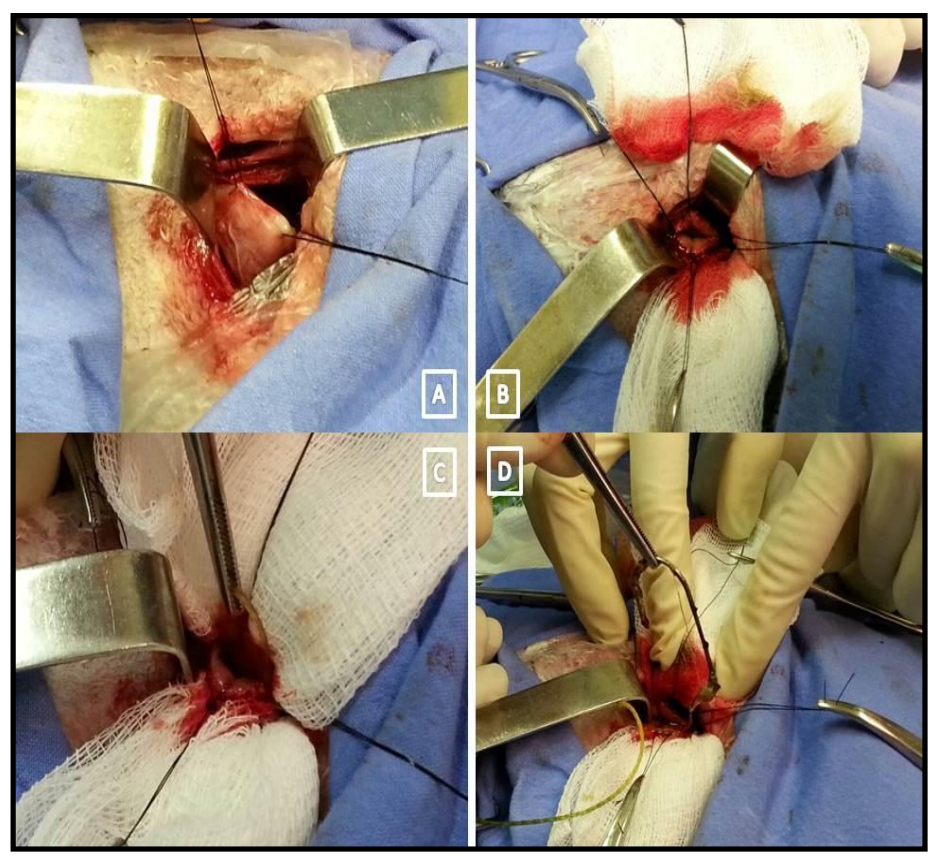

Figure 2. Muscovy duck (Cairina moschata) A. Repair points to facilitate proventriculus manipulation. B. Proventiculus incision with two additional repair points. C. Initiating the removal of the hook by the fishing line. D. Exposure and complete withdrawal of hook and line fishing.

Throughout the postoperative period, until the sutures were removed, the muscovy duck was kept in a dry veterinary stainless-steel cage (120 x $60 \times 60 \mathrm{~cm}$ ) with no access to swimming water (to avoid catheter infection). It had access to a drinking water.

Two days after the surgical procedure, fruit mash supply was started with gelatin and vegetables via gavage, initially $20 \mathrm{~mL}$ per shift, increasing $5 \mathrm{~mL}$ per day up to the limit of $30 \mathrm{~mL}$ per feed. On the fourth postoperative day, solid foods (feed with chopped cabbage leaves) were offered and the animal began to feed voluntarily. Hence, gavage feeding was interrupted. The surgical wound was cleaned daily with $0.5 \%$ chlorhexidine solution followed by an antiseptic ointment. Stitches were removed ten days after surgery.

Two weeks after the surgical procedure, no abnormalities were found on radiographic exam of the coelomic cavity. The animal was clinically well, active, feeding voluntarily and, therefore, releasement to the wild was indicated. It was referred to the Wild Animal Rehabilitation Center (CERAM / UFRGS), which performed the release according to the institution's protocol.

\section{DISCUSSION}

Diagnosis of gastrointestinal foreign body can be made by radiography, endoscopy, palpation or exploratory laparotomy (Gelis, 2006). In our case despite the history of unrestricted access to fishing area and the reported fishing line in the oral cavity (not confirmed by clinical examination), radiographic exam was fundamental to identify the type, size and location of the ingested material (Gelis, 2006; Hoefer and Levitan, 2013).

This information was fundamental for the treatment plan. Despite achieving diagnosis through simple radiographs, we chose to perform contrasted examination to rule out complications that could affect the therapeutic options. Considering the possibility of visceral perforation, iohexol was used as a contrast medium. It has lower chances of causing inflammatory reactions or granulomas (Hoefer and Levitan, 2013), besides having faster transit time than barium (Ernst et al., 1998).

Treatment for foreign body ingestion depends on the impaction severity and/or nature, size, location, type and patient's condition (Hoefer and Levitan, 2013). It can be removed through 
gastrointestinal motility acceleration, endoscopy, the aid of magnets, gastrointestinal lavage or surgery (Degernes et al., 2012, Simova-Curd et al., 2013, Hoefer and Levitan 2013).

The use of gastrointestinal motility accelerators would not be useful for the case, since the hook could generate complications by moving deeply throughout the tract and could lead to an undesirable visceral rupture. In these cases, surgery is a viable option, assessing complications risks such as dehiscence and coelomitis (common in proventriculus and ventricle surgeries) (Simova-Curd et al., 2013; Hoefer and Levitan 2013).

Furthermore, given the high likelihood that a hook-like foreign body is attached to some viscera, surgical treatment is advised (Routh and Sanderson, 2010). It is important to educate people to never pull these objects out through the remaining wire, to avoid deeper attachment or organ laceration. There was no information regarding what the rescuers did to the animal, but there was a possibility that the wire had been pulled out in the expectation of solving the situation. In our case, surgical treatment was chosen because the foreign body was static, since even with preserved gastrointestinal motility the hook did not go through. That was confirmed by serial radiographic examinations.

The choice for left lateral celiotomy in the intercostal region was based on the anatomical position of the foreign body. This region was visually and anatomically more accessible with less viscera. The performed technique was similar to that described in the literature (Forbes, 2002), except for the more cranial location, but the approach was effective. This approach makes it anatomically difficult to have contact with possible contaminating agents of the environment - such as water contaminated by feces -, it allows the wing protection, and it had diminished bleeding and almost had no need for visceral manipulation; Thus allowing a short surgical time - a fact in agreement with the basic principles of bird surgery (Tseng, 2008).

Our study demonstrates that the intercostal access is a viable option that minimizes complications in cases of proventriculus surgery. The most commonly accessed approach for procedures involving the ventricle, proventriculus, gonads, left kidney and oviduct is the conventional lateral flank (Forbes, 2002). Another frequent access to the coelomic cavity in birds is usually the ventral median, however, it presents complications due to dorsal decubitus (Coles, 2007). Another obstacle is the difficulty to visualize the majority of the cavity, as well as the need to rupture caudal and abdominal air sacs (Forbes, 2002; Coles, 2007), a condition that has profound effects on the efficiency of inhalation anesthesia and transoperative heat loss (Forbes, 2002).

The other approaches were not considered because in a ventral midline incision, all the weight of the viscera would overload the suture line and compromise the need to stay in an aquatic environment, necessary to waterfowl (Anderson, 2004). The exposure water and dirt could lead to infection and dehiscence. In the flank approach, it would be difficult to reach the target organ, requiring ventricle traction (Coles, 2007) and possibly the dissection of suspensory ligaments of the proventriculus (Tseng, 2008), an unnecessary situation in our suggested approach.

Regarding analgesia, some studies tested pharmacokinetics and antinociceptive effects of oral and intravenous tramadol in Hispaniolan amazon (Amazona ventralis) and verified antinociception achievement at doses of $5 \mathrm{mg} . \mathrm{kg}^{-1}$

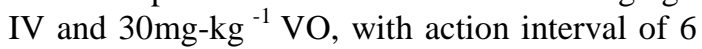
to 8 hours, without adverse effects or sedation (Souza et al., 2012; Geelen et al., 2013). We chose to use $30 \mathrm{mg}^{-\mathrm{kg}^{-1}}$ IM/IV every 12 hours and no behavioral changes were observed in the patient, neither suggestive of pain, nor regarding sedation.

Some authors advise that viscera closure should be done using 4-0 to 6-0 synthetic absorbent suture, in two layers of continuous or interrupted pattern (Forbes, 2002; Tseng, 2008). In our case, synthesis was performed using 3-0 synthetic absorbable suture in a single layer of single isolated pattern and no complications were observed.

The use of antimicrobial in the post-surgical period is essential to avoid infections (Tseng, 2008; Routh and Sanderson, 2010). We chose a broad spectrum antibiotic association with longer action time, that allows lower number of physical restraints for drug application - an important 
feature when it comes to wild animals. In this report, gavage feeding was started from the second postoperative day, different from what is recommended by the literature (Tseng, 2008; Routh and Sanderson, 2010), to avoid overloading of the affected viscus. However, support fluid therapy and sucralfate administration were maintained as gastrointestinal mucosal protector to minimize post-operative stress until the patient regained voluntarily feeding.

\section{CONCLUSION}

This case report demonstrates that intercostal access can be used for removal of foreign bodies located in the proventriculus without trans or postoperative complications, such as hemorrhage or dehiscence. It may be a new option for removal of foreign bodies, for demonstrating benefits compared to the conventional technique. In addition, it is a quick procedure which minimizes surgical and anesthetic risks and can be considered in the approach of other individuals of the same specie or another Anatidae.

\section{REFERENCES}

ANDERSON D.L. Waterfowl Rehabilitation: a primer for veterinarians. Semin. Avian Exot. Pet Med. v.13, p.213-222, 2004.

BRASIL. Ministério da Pesca e Aquicultura. Pesca amadora, 2014. Available in: <http://www.mpa.gov.br/index.php/pescampa/amador a/pesca-amadora-no-brasil/apresentacao $>$. Accessed in: 05 Feb.14.

CÂNDIDO, M.V. Anseriformes (marreco, pato e ganso). In: CUBAS, Z.S., SILVA, J.C.R., CATÃODIAS, J.L. (Eds.). Tratado de animais selvagens. 2.ed. São Paulo: Roca, 2014. p.330-353.

COLES, B.H. Surgery. In: COLES B.H. Essentials of avian medicine and surgery. Ames, Iowa: Blackwell, 2007. p.155-159.
DEGERNES, L.A.; WOLF, K.N.; ZOMBECK, D.J. et al. Ventricular diverticula formation in captive parakeet auklets (Aethia psittacula) secondary to foreign body ingestion. J. Zoo Wildl. Med., v.43, p.889-897, 2012.

ERNST, S.A.; GOGGIN, J.M.A.; BILLER, D.S.A. et al. Comparison of iohexol and barium sulfate as gastrointestinal contrast media in mid-sized psittacine birds. J. Avian Med. Surg., v.12, p.16-20, 1998.

FORBES, N.A. Avian gastrointestinal surgery. Semin. Avian Exot. Pet Med., v.11, p.196-207, 2002.

GEELEN, S.; GUZMAN, D.S.M.; SOUZA, M.J. et al. Antinociceptive effects of tramadol hydrochloride after intravenous administration to Hispaniolan Amazon parrots (Amazona ventralis). Am. J. Vet. Res., v.74, p.201-206, 2013.

GELIS, S. Evaluating and treating the gastrointestinal system In: HARRISON, G.J.; LIGHTFOOT, T.L. Clinical avian medicine. Palm Beach, Florida: Spix Publishing, 2006. p.411-440.

GUZMAN, D.S.M.; SOUZA, M.J.; BRAUN, J.M. et al. Antinociceptive effects after oral administration of tramadol hydrochloride in Hispaniolan Amazon parrots (Amazona ventralis). Am. J. Vet. Res., v.73, p.1148-1152, 2012.

HOEFER, H.; LEVITAN, D. Perforating foreign body in the ventriculus of an umbrella Cockatoo (Cacatua alba). J. Avian Med. Surg., v.27, p.128-135, 2013.

ROUTH, A.; SANDERSON, S. Aves aquáticas. In: TULLY, T.N.; DORRESTEIN, G.M.; JONES, A.K. Clínica de aves. Rio de Janeiro: Elsevier, 2010.

SIMOVA-CURD, S.; FOLDENAUER, U.; GUERRERO, T. et al. Comparison of ventriculotomy closure with and without a coelomic fat patch in Japanese quail (Coturnix coturnix japonica). J. Avian Med. Surg., v.27, p.7-13, 2013.

SOUZA, M.J.; GUZMAN, D.S.M.; PAUL-MURPHY, J.R.; COX, S.K. Pharmacokinetics after oral and intravenous administration of a single dose of tramadol hydrochloride to Hispaniolan Amazon parrots (Amazona ventralis). Am. J. Vet. Res., v.73, p.1142-1147, 2012.

TSENG, F.S. Avian anesthesia and surgery. 2008. Available in: <http://ocw.tufts.edu/Content/60/ lecturenotes/796181>. Accessed in: 3 Mar.2017. 